\title{
HYPERGONADOTROPIC HYPOGONADISM, PROGRESSIVE EARLY-ONSET SPINOCEREBELLAR ATAXIA, AND LATE-ONSET SENSORINEURAL HEARING LOSS: CASE REPORT AND LITERATURE REVIEW
}

Sarikaya E, ${ }^{1}$ Ensert $\mathrm{CG},{ }^{2}$ Gulerman $\mathrm{HC}^{1}$

*Corresponding Author: Esma Sarikaya, Centre for Reproductive Medicine, Zekai Tahir Burak Women's Health Research and Education Hospital, Talatpasa Bulvari Hamamonu 06230, Ankara, Turkey; Tel.: +90-312310-3100; Fax: +90-312-312-4931; E-mail: sudesarikaya@hotmail.com

\begin{abstract}
The association of ataxia, hypergonadotropic hypogonadism and hearing loss is extremely rare. Considerable heterogeneity exists in the literature of the neurological manifestations, age of onset, clinical severity and associated abnormalities. We describe a 24-yearold woman with secondary hypergonadotropic amenorrhea, early-onset progressive spinocerebellar ataxia (SCA), late-onset sensorineural hearing loss and normal intelligence and compare it with reported cases.
\end{abstract}

Keywords: Cerebellar ataxia, Hearing loss, Sensorineural, Premature ovarian failure

\section{INTRODUCTION}

The association of hypogonadism and cerebellar ataxia (Gordon Holmes syndrome) was first recognized as a distinct, rare, autosomal recessive syndrome in 1907 [1]. In the majority of cases the gonadal deficiency is secondary to decreased pituitary production of gonadotropins.

The association of hypergonadotropic hypogonadism in females and sensorineural hearing loss (SNHL)

Centre for Reproductive Medicine, Zekai Tahir Burak Women's Health Research and Education Hospital, Ankara, Turkey

2 Department of Neurology, Zekai Tahir Burak Women's Health Research and Education Hospital, Ankara, Turkey in females and males was first described in 1951 as Perrault syndrome (PS), which is an extraordinary genetic syndrome that is inherited in an autosomal recessive manner. Affected females have streak gonads in place of their ovaries and they consequently have primary amenorrhea. Some patients also have neurological manifestations, including mild mental retardation and cerebellar and peripheral nervous system involvement. The exact frequency of the neurological abnormalities seen with PS cannot be ascertained since several reports did not include a description of either a normal or abnormal neurological examination. More recent studies have asked whether the neurological signs in some of the patients are a coincidental finding or part of the syndrome [2-4]. Some researchers proposed a possible classification of PS to type I, static and without neurological disease, and type II, with progressive neurological disease [5].

We here document a patient with association of ataxia hypergonadotropic hypogonadism and hearing loss (AAHH). Our patient could be classified as atypical type II PS due to her secondary amenorrhea and progressive neurological deficits. But to avoid confusion with the overlapping syndromes, we preferred to use the terminology of the AAHH instead of type II PS, and ascribe this association as a completely different clinical entity.

As a result of our literature search, we realized that there was huge variability in the clinical severity, neurological picture, age at onset, endocrine findings, 
progression of symptoms, presence of associated abnormalities and proposed pathogenetic mechanisms of the reported cases. We also realized that AAHH is extremely rare and also part of well described autosomal recessive syndromes other than PS [6-9] (Table 1).

\section{LITERATURE SEARCH}

A Medline, PubMED and Cochrane Library search of Perault syndrome in the (English) literature, cited between the years 1970 and 2011, was performed to make differential diagnosis of our case. The medical subject headings (MESH) terms and established abbreviations of Perrault syndrome, hypergonadotropic amenorrhea, sensorineural deafness and ataxia were included to collect the relevant citations. In addition, a hand search of pertinent references was performed.

Amor et al. [3] reviewed the cases of the rare association of ataxia with hypergonadotropic hypogonadism $(\mathrm{AAH})$ and documented only 15 cases. In this study, additional to the Amor et al. [3] association, the cases with hearing loss were also reviewed. Including the patient in the present report, 14 cases with AAHH have been documented in the literature, sometimes with additional abnormalities (Table 2) [4,5,10-19].

This review aimed to summarize the actual knowledge about the genetic background, pathomechanisms, clinical manifestations, diagnostic approach- es and therapeutic strategies concerning AAHH. The purpose of our study was to make physicians familiar with the constellation of clinical findings suggestive of syndromes associated with AAHH.

\section{CASE REPORT}

A 24-year-old Caucasian female was admitted to the Reproductive Medicine Outpatient Clinic with primary infertility for 2 years as the chief complaint. Written informed consent was obtained from our patient for the publication of this case report and any accompanying images. She showed normal growth and development and manifested age-appropriate pubertal development. Her menarche started when she was 12 years old, and the cycles were regular until she was 18 years old. Neurological symptoms began in the first decade of life with disequilibrium, poor balance with falling and dysarthria. Two years later clumsiness in fine finger movements and writing developed. Her symptoms progressed and she experienced several falls, but could walk without walking aids. Her menses became irregular and stopped when she was 22 years old and she was diagnosed as having premature ovarian insufficiency.

Her parents were unrelated. Her father was a healthy man who died at 66 years of age. Her 69 -yearold mother was said to be healthy until she was diagnosed as having Parkinson's disease. There was no

Table 1. Autosomal recessive syndromes associated with ataxia hypergonadotropic hypogonadism and hearing loss.

\begin{tabular}{|l|l|l|l|}
\hline $\begin{array}{l}\text { Autosomal Recessive } \\
\text { Syndromes }\end{array}$ & Amenorrhea & Neurological Manifestations & Associated Abnormalities \\
\hline Perrault syndrome & primary & $\begin{array}{l}\text { nystagmus, sensory polyneuropathy, } \\
\text { mental retardation, delay in walking, } \\
\text { early frequent falls }\end{array}$ & $\begin{array}{l}\text { right bundle branch block, Marfanoid } \\
\text { habitus, pes equinovarus, short stature, } \\
\text { scoliosis }\end{array}$ \\
\hline $\begin{array}{l}\text { Richards-Rundle } \\
\text { syndrome }\end{array}$ & primary & $\begin{array}{l}\text { peripheral muscle wasting, nystagmus, } \\
\text { dementia, mental retardation }\end{array}$ & $\begin{array}{l}\text { kyphosis or scoliosis, talipes } \\
\text { equinovarus, claw-hand, ketoaciduria }\end{array}$ \\
\hline Alström syndrome & primary & - & $\begin{array}{l}\text { blindness, nystagmus, photophobia, } \\
\text { dilated cardiomyopathy, multi organ } \\
\text { failure, type 2 diabetes mel-litus, short } \\
\text { stature, growth hormone deficiency, } \\
\text { alopecia }\end{array}$ \\
\hline $\begin{array}{l}\text { Mitochondriopathies } \\
\text { cardiomyopathy, short stature, cataracts, } \\
\text { diabetes mellitus, diabetes insipidus, } \\
\text { dysphagia, renal failure, mental } \\
\text { retardation }\end{array}$ \\
\hline $\begin{array}{l}\text { Wolfram's syndrome } \\
\text { (DIDMOAD) }\end{array}$ & primary & epilepsy, sensory neuropathy & $\begin{array}{l}\text { diabetes mellitus, diabetes insipidus, } \\
\text { optic atrophy, psychiatric illnesses }\end{array}$ \\
\hline
\end{tabular}


Table 2. Case reports associated with ataxia, hypergonadotropic hypogonadism and hearing loss.

\begin{tabular}{|c|c|c|c|c|}
\hline Reference & $\begin{array}{l}\text { Amenorrhea } \\
\text { (years) }\end{array}$ & $\begin{array}{l}\text { Onset of Ataxia } \\
\text { (in years) }\end{array}$ & Neurological Manifestations & Associated Abnormalities \\
\hline 10 & primary & 2 & nystagmus & $\begin{array}{l}\text { pes equinovarus, short stature, growth } \\
\text { hormone deficiency }\end{array}$ \\
\hline 11 & primary & not reported & mental retardation & - \\
\hline 12 (case 4) & primary & 4 & grand mal seizures, nystagmus & - \\
\hline 13 & primary & not reported & $\begin{array}{l}\text { dyspraxia, choreatic movements, } \\
\text { mental retarda-tion, sensory } \\
\text { neuropathy }\end{array}$ & amelogenesis imperfecta \\
\hline 14 & primary & infant & epilepsy & optic atrophy \\
\hline 15 & primary & 1 & $\begin{array}{l}\text { mental retardation, saccadic } \\
\text { dysmetria }\end{array}$ & retinal dystrophy \\
\hline $\begin{array}{l}3(\text { case } 1) \\
3(\text { case } 2)\end{array}$ & $\begin{array}{l}\text { secondary (16) } \\
\text { secondary (14) }\end{array}$ & $\begin{array}{l}20 \\
30\end{array}$ & nystagmus & - \\
\hline 4 & primary & 13 & - & prognathism \\
\hline 16 (case 2) & secondary (13) & 9 & $\begin{array}{l}\text { dysarthria, ophthalmoplegia, } \\
\text { borderline mental retardation, } \\
\text { reduced muscle strength, joint } \\
\text { hyper-laxity, hyperextensibility } \\
\text { polyneuropathy, nys-tagmus, } \\
\text { dysarthria, mental retardation, } \\
\text { severe atrophy of the vermis and } \\
\text { cerebellar hemispheres }\end{array}$ & $\begin{array}{l}\text { sinus tachycardia, right ventricular } \\
\text { hypertrophy }\end{array}$ \\
\hline $\begin{array}{l}16(\text { case } 3)^{\mathrm{a}} \\
20 \\
5\end{array}$ & primary & $5-10$ & $\begin{array}{l}\text { polyneuropathy, nystagmus, } \\
\text { dysarthria, mental retardation, } \\
\text { severe atrophy of the vermis and } \\
\text { cere-bellar hemispheres }\end{array}$ & $\begin{array}{l}\text { short stature, cubitus valgus, short } 5 \text { th } \\
\text { meta-carpals, high-arched palate and } \\
\text { micrognathia, scoliosis, pes cavus }\end{array}$ \\
\hline 18 & primary & not reported & - & - \\
\hline 19 (case 2) & primary & 2 & $\begin{array}{l}\text { nystagmus, ophthalmogia, bilateral } \\
\text { ptosis, neurophathy, mental } \\
\text { retardation }\end{array}$ & $\begin{array}{l}\text { progressive flexion of the phalanges } \\
\text { of the } 5 \text { th finger of the right hand, } \\
\text { behavioral changes }\end{array}$ \\
\hline This study & secondary & 9 & $\begin{array}{l}\text { nystagmus, peripheral } \\
\text { polyneuropathy }\end{array}$ & pes equinovarus \\
\hline
\end{tabular}

${ }^{a}$ Case 3 of [16] was also reported by Pierce et al. [5] and Pallister and Opitz [20].

evidence of spinocerebellar ataxia (SCA) or hypogonadism or of neurological, endocrinological, ocular or skeletal disease in the family except that her 34-yearold unmarried brother who had a hearing problem and ataxia that started at 7 years of age. Her 22- and 20-year-old sisters were normal.

Clinical examination revealed a lean young woman of normal intelligence and appearance with normal secondary sexual characteristics and normal height (164 $\mathrm{cm})$. Her external genitalia were those of a normal female, without clitoris enlargement. Breast development was at Tanner stage 5, and pubic hair development at
Tanner stage 4. There was no hirsutism or abnormal pigmentation. She presented no clinical signs of Turner syndrome. She was normocephalic with no facial dysmorphism. She had mild dysarthria and bilateral cerebellar ataxia affecting mainly the lower limbs. Muscle tone and power were normal in the limbs, with reflexes having reduced amplitude. There was mild dysmetria in the upper limbs on finger-nose testing. Sensation was reduced to light touch, pinprick and vibration. On electromyography, axonal sensorimotor peripheral polineuropathy was detected in the lower limbs. She had an abnormal gait and club foot deformity which led to poor balance with 
falling and skin problems in the lower limbs. There was horizontal gaze-evoked nystagmus bilaterally. The diagnosis of grade 1 SCA was made after clinical examination by an experienced neurologist (CGE).

She did not approve of molecular analysis for expansions at the SCA 1, 2, 3, 6, 7 and Friedreich's ataxia loci since her primary complaint was her infertility and not her neurological problems and the results would not change the treatment she would receive. Neither optic nerve atrophy nor cataracts were detected on fundoscopic examination. On ultrasound examination of the pelvis, the uterus was normal and the ovaries were slightly reduced in size. There was no cerebellar atrophy and the sella turcica was normal on magnetic resonance imaging. There was no kyphosis or scoliosis.

Endocrinological assessment showed markedly raised serum levels of luteinizing hormone: $35.9 \mathrm{U} / \mathrm{L}$, follicle stimulating hormone: $110.6 \mathrm{U} / \mathrm{L}$ and low estradiol: $14 \mathrm{pg} / \mathrm{ml}$ (normal ranges: 5-60 U/L, 5-30 U/L and $20-240 \mathrm{pg} / \mathrm{ml}$, respectively) indicating a hypergonadrophic form of hypogonadism. Adrenal and thyroid function, hematological and biochemical studies and autoimmune panels were within normal levels. Results of metabolic evaluation were normal, including vitamin E, folate and B12 levels, $\alpha$-fetoprotein, very long chain fatty acids and phytanic acid, lysosomal enzymes, amino and organic acids. Serum ammonia levels were normal with arterial $\mathrm{pH}$ measurements showing no signs of an acidosis. Serum CK and lactate levels were also normal. An echocardiogram (ECG) showed no prolonged Q-T interval. Smell testing was normal. Her karyotype was 46XX.

On audiometry, pure tone threshold assessment revealed bilateral SNHL in the mid and high frequencies $(>3.5 \mathrm{kHz})$ (Figure 1). Tympanometry was normal. She was not advised to use a hearing aid. There were no previous risk factors for hearing loss.

\section{DISCUSSION}

We here document a patient with an unusual pattern of AAHH because of her secondary amenorrhea and normal intelligence. She also had nystagmus and clinical and electrophysiological evidence of a progressive peripheral motor and sensory neuropathy, and club foot deformity. We compared our case with the reported cases of this association.

It is discussed in the literature whether AAHH is part of a separate clinical entity or should be included

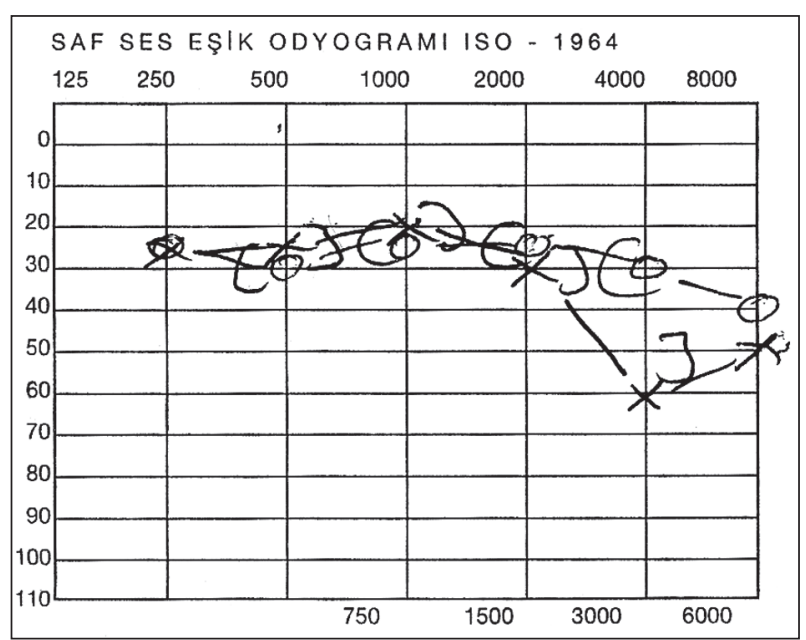

$\mathrm{X}$ axis: hearing level $(\mathrm{dB})$; $\mathrm{y}$ axis: frequency (Hertz).

Figure 1. Pure-tone audiometry showing bilateral sensorineural hearing loss in bass frequency.

within the spectrum of PS. Some cases were designated as variants of Gordon Holmes type ataxia [12], others reported as a variant of PS $[2,5,10,13,15,16,18,19]$, others reported as an association $[3,4]$, and others reported as a recessive disorder comprising ovarian dysgenesis and sensorineural deafness, with neurological abnormalities present in a minority of cases [20]. We preferred to use the term AAHH instead of type II PS, as did Amor et al. [3] and Georgopoulos et al. [4].

As in our patient, the time of the clinical diagnosis of AAHH in most cases took place after the apparition of a secondary amenorrhea or a delayed puberty in a deaf female. The mean age at diagnosis was 22 years in the literature.

Our patient had no facial dysmorphism, optic atrophy, epilepsy, skeletal or other endocrinolgical problems. This ruled out Richards-Rundle, Alström, Marinesco-Sjögren's syndromes, Blepharophimosis-ptosisepicanthus inversus syndromes mitochondriopathies and Wolfram's syndrome [diabetes insipidus, diabetes mellitus, optic atrophy and deafness (DIDMOAD)]. Kallman's syndrome was also ruled out as there was no smell disorder. The normal serum vitamin E levels excluded ataxia due to isolated vitamin E deficiency or hypobetalipoproteinemia. The normal serum very long chain fatty acids and phytanic acid levels excluded Zellweger syndrome and Refsum's disease. The normal serum CK and lactate levels excluded coenzyme Q10 (CoQ10) deficiency. Serum ammonia levels were normal with arterial $\mathrm{pH}$ measurements showing 
no signs of an acidosis. This excluded multiple acylCoA dehydrogenase deficiency or glutaric aciduria type II [21-25]. Since her karyotype was 46XX, ovarian dysgenesis was not attributed to a chromosomal abnormality.

Our patient manifested age-appropriate pubertal development. Her secondary amenorrhea was atypical since most of the reported cases of AAHH, manifested by primary amenorrhea. Other reported secondary amenorrhea cases of AAHH, were sisters in the study by Amor et al. [3] and patient 2 in the study by Fiumara et al. [16]. In PS, the cardinal manifestation is primary amenorrhea and an ovarian dysgenesis has been reported in all female cases. There are a few more reported secondary amenorrhea cases of PS but they have no ataxia. Marlin et al. [19] reported that the amenorrhea was primary in 24/28 PS patients but can also occasionally be secondary. The exact frequency of the secondary amenorrhea cases seen with PS cannot be ascertained since several reports did not include a description of either secondary or primary amenorrhea. The same problem is also present for the associated neurological problems.

Moreover, Fiumara et al. [16] reported that girls with PS generally have menarche and a few regular initial periods before becoming amenorrheic, thus suggesting that ovaries develop to some extent, then undergo progressive atrophy but they did not explain how they reach such a conclusion. The present case and those of Amor et al. [3], were similar in that they had secondary amenorrhea and their intelligence was normal, contrary to the mental impairment in PS, Richards-Rundle syndrome and other case reports $[5,11,13,15,16,19]$. However, our case differs from those of Amor et al. [3], as her onset of neurological symptoms was in childhood. A childhood onset of neurological symptoms was the common feature in all of the previous reports.

\section{DIFFERENTIAL DIAGNOSIS}

Phenotypic overlap and inter familial variability make the hereditary ataxias a notoriously difficult group of disorders to classify. New gene loci, which are linked to SCAs, are discovered every other day. Endocrine dysfunction is a common clinical feature in these patients, with hypogonadism occurring in approximately $5 \%$ [26]. The same problem is also present for SNHL, which is a component of more than 400 syndromes, and, so far, more than 30 genes associated with syndromic hearing loss have been identified. To date, more than 70 loci have been reported for non syndromic deafness, including approximately 40 autosomal dominant, 30 autosomal recessive, and eight $\mathrm{X}$ linked, and approximately 30 genes have been cloned. Mutations in GJB2, the gene that encodes the connexin 26 protein, are the most common cause of recessive deafness in the United States, and dominant low-frequency SNHL is most commonly caused by mutations in the Wolfram's syndrome 1 gene. Usher syndrome is the most frequent cause of combined deafness and blindness in the industrialized world [27].

Association of ataxia and hypergonadotropic hypogonadism and hearing loss is extremely rare and part of well described autosomal recessive syndromes other than PS [6-9] (Table 1). Other syndromes that exhibit two or more signs of AAHH are: trinucleotide repeats disorders; fragile $\mathrm{X}$ syndrome (CGG repeat), Friedreich's ataxia (GAA repeat) and five SCAs (1, 2, 3, 6 and 7) (CAG repeat), myotonic dystrophy (DM/ Curschmann-Steinert disease), proximal myotonic myopathy (PROMM or Ricker's syndrome) (CTG repeats) [28], ciliopathies; Alström syndrome, BardetBiedl syndrome [29], the neurodegenerative mitochondriopathies; Huntington's disease, Charcot-Marie-Tooth (CMT), Leber's hereditary optic neuropathy, Kearns-Sayre syndrome (KSS), maternally inherited Leigh syndrome (MILS), and the neuropathy, ataxia, and retinitis pigmentosa (NARP) syndrome and other mitochondriopathies; Wolfram's syndrome [30], muscle lipid diseases; lipid storage myopathy (LSM), multiple acyl-CoA dehydrogenase deficiency, glutaric aciduria type II, and neutral lipid storage disease with myopathy, $\beta$-oxidation cycle defects and deficiencies of carnitine palmitoyltransferase II (CPTH) and very long chain acyl-CoA dehydrogenase (VLCAD) [31]. Refsum's disease (phytanic acid storage disease), and Zellweger syndrome (cerebro-hepato-renal syndrome), Uscher, Alport, Cockayne, Flynn-Aird, Hurler (MPS-1), Kearns-Sayre (CPEO), Norrie, 4H (hypomyelination with hypogonadotropic hypogonadism and hypodontia), Sohval-Soffer, Crandall, WoodhouseSakati, Marinesco-Sjögren's, CAPOS syndromes, galactosemia and hereditary motor sensory neuropathies (HSMN)[16,23,33-38].

In a few reports, several moleculer analyses have been made for the differential diagnosis of these patients: Pierce et al. [5] applied whole-exome sequenc- 
ing to identify the gene responsible for PS and found mutations in 17 $\beta$-hydroxysteroid dehydrogenase type 4 [also known as D-bifunctional protein (HSD17B4/ DBP)], which is also detected in Zellweger syndrome [23]. They have also found mutations in mitochondrial histidyl tRNA synthetase HARS2 [38]. Nishi et al. [10] found no evidence of mitochondrial disease on a muscle biopsy, including respiratory enzyme assays; no ragged red fibers were found on muscle biopsy and there was only mild type IIB atrophy, a non specifc finding in many types of upper motor neuron lesions. In the evaluation by Fiumara et al. [16] none of the known mitochondrial or CMT mutations were present in the DNA of patient 1. Muscle biopsy showed atrophy with fat replacement. They also performed sural nerve biopsy in one patient (SM) and found severe loss of myelinated fibers with segmental demyelination and remyelination and scattered axonal degeneration suggestive of a form of hereditary motor sensory neuropathy (HSMN). Mitochondrial testing on patient 1 (LK) for MELAS 3243, SNHL-1555 and -7445 also did not show any of the mutations known to cause the mitochondrial encephalomyopathy, lactic acidosis, and stroke-like episodes or some form of SNHL [16]. Marlin et al. [19] sequenced the whole mitochondrial genome, GJB2 (the most frequent form of isolated hearing impairment), AOA1, POLG, FRDA, (genes implicated in ataxia or ophthalmoplegia) and FOXL2 (a gene responsible for a premature ovarian failure), and did not find any mutation in patient 2 . In one female with this association, partial deficiency of the mitochondrial enzyme cytochrome $\mathrm{c}$ oxidase was demonstrated by De Michele et al. [12]. Gironi et al. [39] reported two brothers who had late-onset progressive ataxia and hypergonadotropic hypogonadism associated with muscle CoQ10 deficiency.

Before starting further laboratory investigations, we think clinical and neurological examinations must be fully performed in such cases. Long-term follow up is very important in these patients since some clinical manifestations appear later in life. It is also important to collect details on the general health, hearing, menstrual history and to report the presence of morphologic abnormalities of the ear, eye, face, or other organ systems, mental retardation, ataxia, epilepsy, Parkinson's disease, autism of the relatives from both parental lines. It is also relevant to check for consanguinity and family ethnic background. This simple approach will provide the opportunity to recognize associated syn- dromes and evidence of the basis behind the initiation of further laboratory investigations. The assessment of a patient with AAHH requires a multidisciplinary approach and must include advice and support to the parents, and genetic counseling aimed at optimizing the use of the most adequate clinical resources. The laboratory tests must be confirmed according to clinical suspicion. Before making costly molecular analyses, simple blood tests for glucose, vitamin E, folate and B12 levels, $\alpha$-fetoprotein, very long chain fatty acids and phytanic acid, lysosomal enzymes, amino and organic acids serum ammonia, arterial $\mathrm{pH}$ levels, and X-rays of the skeleton should be done. Performing ECG, muscle biopsy, measurement of mitochondrial enzyme cytochrome c oxidase and muscular CoQ10 levels and DNA analysis for trinucleotide expansions at the SCA 1, 2, 3, 6, 7 and Friedreich's ataxia loci, and looking for mutations in HSD17B4 for a number of similar cases will give valuable information about the pathogenesis and differential diagnosis of this association. The late-onset of SNHL in many reported cases underlines the need for careful examination of acoustic acuity in cases of cerebellar ataxia and hypogonadism. The audiograms are also important to guide patient rehabilitation.

The pathogenetic mechanism of AAHH is not yet fully understood. Considerable heterogeneity exists in the literature on the neurological manifestations, onset age, progression of symptoms, clinical severity and presence of associated abnormalities such as mental retardation (PS, Richards-Rundle syndrome) [5,11-15,19], epilepsy (mitochondriopathies) [12,14], nystagmus [3,10,12,19, present study], cataract, optic atrophy, retinal dystrophy or blindness (Alström and Wolfram's syndrome, mitochondriopathies) [14,15], and endocrine anomalies (Wolfram's, Alström, Richards-Rundle syndromes, mitochondriopathies) [10], short stature (Alström syndrome) [5,10], cardiac anomalies (PS and mitochondriopathies) in this association. This heterogeneity may be reflecting different degrees of severity within the entity of ovarian dysgenesis and neurological impairment and favors the hypothesis that AAHH is a heterogeneous syndrome. It is therefore very unlikely that cerebellar ataxia and hypogonadism are linked to a common genetic defect. As the physiopathology of PS is still unknown, the question remains whether one gene is implicated in all the different clinical forms of PS (with and without neurological symptoms) or if there are at least two different genes 
responsible for two different clinical entities. It is more reasonable to ascribe this association as a clinical entity with a different, yet not fully understood, pathogenetic mechanism in which the involvement of different genotypes may lead to the same or similar phenotypic manifestations. Association of ataxia hypergonadotropic hypogonadism and hearing loss could be caused by both a malfunction of the mitochondria and of myelination. Depending on the genes involved, it may have autosomal recessive or mitochondrial inheritance. The inter familial variation of both the severity of hearing loss and the onset of amenorrhea, and neurological symptoms in individuals with AAHH may turn out to be due to environmental or genetic factors influencing the effect of mutations.

Proposed Causative Pathogenic Mechanisms

\section{Were as Follows:}

1) Polymorphisms within the mitochondrial genome might lead to impaired energy generation and to an increased amount of reactive oxygen species, having susceptibility in several diseases. Mitochondria produce most of the cell's supply of adenosine triphosphate (ATP), by means of the oxidative phosphorylation machinery, which comprises electron transport chain (ETC) and ATP synthase. The ETC dysfunction leads to reduced ATP production, impaired calcium buffering and increased generation of reactive oxygen species (ROS). Mitochondria have their own DNA; the mitochondrial DNA (mtDNA) carries 37 genes: 22 encoding for mitochondrial transfer RNAs (tRNAs) (for the 20 standard amino acids, plus an extra gene for leucine and serine), two for ribosomal RNAs (rRNAs) and 13 encoding for polypeptides subunits of complexes of the respiratory chain system, seven of these belong to complex I or NADH dehydrogenase (ND1, ND2, ND3, ND4, ND4L, ND5, ND6), one to complex III or cytochrome c reductase, three to complex IV or cytochrome c oxidase (COX I, COX II and COX III) and two to complex V or ATP synthase (ATPase6 and ATPase8). Increased production of ROS damages cell membranes and further accelerates the high mutation rate of mtDNA. Mitochondrial genetics differs from Mendelian genetics in three major aspects: maternal inheritance, heteroplasmy and mitotic segregation. Mitochondria are inherited in humans via the female line, transmitted as a non recombining unit by maternal inheritance [40].

There is significant evidence that the pathogenesis of several neurodegenerative diseases, including
Parkinson's disease, Alzheimer's disease, Friedreich's ataxia, multiple sclerosis and amyotrophic lateral sclerosis, may involve the generation of reactive oxygen species and/or reactive nitrogen species associated with mitochondrial dysfunction [40]. Leipnitz et al. [41] reported that oxidative stress is elicited in vitro by phytanic acid (Phyt) that accumulates in Refsum disease and other peroxisomal diseases. Phytanic acid increased thiobarbituric acid-reactive substances (TBA-RS) levels, carbonyl content and sulfhydryl oxidation, and decreased concentrations of glutathione (GSH). This effect was prevented by the antioxidants $\alpha$-tocopherol and melatonin, suggesting the involvement of free radicals [41].

In one female with this association, partial deficiency of the mitochondrial enzyme cytochrome c oxidase was demonstrated by De Michele et al. [12]. Primary MCPs are either due to sporadic or inherited mutations in nuclear or mitochondrial DNA located genes. The MCPs should be considered in any patient with unexplained progressive multi system disorder in addition to AAHH [9].

2) It can be related to the defect of a gene producing a protein or other product that affects both granulosa cells, neurons and hearing function. Proteins mentioned in the literature were wolframin, usherin, myosin, harmonin, cadherin 23, protocadherin 15, SANS, whirlin, VLGR1b Clarin-1, D-bifunctional protein (DBP) GPR98 proteins, connexin 26, neuronal proteins, mitochondrial protein, protein zero, norrin, huntington, frataxin, MKS1 and meckelin.

In fragile $\mathrm{X}$-associated tremor/ataxia syndrome (FXTAS), which is one of the most common singlegene forms of gait ataxia and tremor in older males; pre mutation in FMR1 causes the gene to make abnormally increased amounts of messenger RNA. This can be toxic to certain brain cells. A similar toxic mechanism might impair ovarian function and lead to hypergonadotropic hypogonadism [42]. Mutations in the SIL1 gene on chromosome 5q31 cause Marinesco-Sjögren's syndrome and the loss of SIL1 function results in accumulation of unfolded proteins that are harmful to the cell [43].

Mutations in the GALE genes on chromosome 1p36-p35, GALK1 genes on chromosome 17q24, and GALT genes on chromosome 9p13 cause galactosemia. In galactosemia, hypergonadotropic hypogonadism may be due to toxic effect of galactose or its metabolites to the ovarian parenchyma [44]. 
Friedreich's ataxia and Huntington's disease are classified in the neurodegenerative mitochondriopathies and trinucleotide repeat disorders. Friedreich's ataxia is caused by a GAA repeat expansion and mutations in the FXN gene on chromosome 9 that encodes frataxin. Frataxin is a mitochondrially targeted protein that is an iron chaperone and plays a role in mitochondrial iron handling which requires ETC constituents $[45,46]$.

Huntington's disease is caused by a CAG repeat expansion in one copy of the Huntingtin gene on chromosome 4, which encodes a protein called huntingtin that has been shown to physically associate with mitochondrial membranes and interfere with mitochondrial calcium handling. Huntingtin has been proposed to interfere with mitochondrial biogenesis by disrupting peroxisome proliferator activated receptor $\gamma$ coactivator $1 \propto$ (PGC-1a), a transcription co-activator that facilitates mitochondrial biogenesis $[47,48]$.

A mutation in the NDP gene causes Norrie disease. This gene encodes a secreted protein with a cysteinknot motif that activates the $\mathrm{Wnt} / \beta$-catenin pathway. The protein forms disulfide-linked oligomers in the extracellular matrix. For the normal development of the eye and other body systems, norrin is believed to be crucial. Norrin also appears to be crucial in the specialization of the cells of the retina and the establishment of a blood supply to the inner ear and the tissues of the retina [49].

Mutations in HSD17B4 type 4 leads to a fatal form of Zellweger syndrome and may be PS [5,23]. Dbifunctional protein (DBP) and multifunctional protein 2 (MFP-2) encoded by HSD17B4, is a multi functional peroxisomal enzyme involved in fatty acid $\beta$-oxidation and steroid metabolism $[5,23]$.

The WFS1 or wolframin gene provides instructions for making the wolframin protein which is located in the endoplasmic reticulum. More than 30 WFS1 mutations have been identified in individuals with a form of non syndromic deafness called DFNA6. Researchers have identified more than 100 WFS1 mutations that cause Wolfram syndrome. Some mutations delete or insert DNA from the WFS1 gene. As a result, little or no wolframin is present in cells. Other mutations replace one of the amino acids used to make wolframin. These mutations appear to reduce wolframin activity dramatically [50].

The USH2A gene encodes usherin protein and possesses laminin epidermal growth factor as well as fibronectin type III domains. Laminins are the major non collagenous components of basement membranes that mediate cell adhesion, growth, migration and differentiation. The discovery of three putative missense mutations (C319Y, N346H and C419F) in the laminin type VI domain of this protein mark this region for a potentially significant functional role in the cochlea and retina. Netrins are small diffusable proteins that control guidance of central nervous system commissural axons at the midline and peripheral motor axons. A homolog of netrin in C. elegans, UNC-6, is one of the cues in the extracellular matrix that guides dorsoventral migrations of pioneer axons and migrating cells along the body wall on the epidermis [51].

Mutations in 35delG, GJB2, the gene that encodes the connexin 26 protein a gap junction protein that is assumed to be a component of the potassium recycling pathway in the inner ear, are the most common cause of recessive deafness in the United States. To date, 48 recessive and seven dominant disease-causing GJB2 mutations have been identified in the 35 delG allele, and is particularly common in Caucasian populations [52].

Charcot-Marie-Tooth disease (when associated with essential tremor and ataxia, called Roussy-Levy syndrome), which is the most common inherited neurological disorder, is caused by mutations that cause defects in neuronal proteins. The most common cause of CMT (70-80\% of cases) is the duplication of a large region in chromosome $17 \mathrm{p} 12$ that includes the gene PMP22. Some mutations affect the gene MFN2, which codes for a mitochondrial protein [53].

3) An inherited unstable trinucleotide repeat disorder, which is caused by an expansion of repetitive three bases in the causative gene, likely shares a common pathogenesis caused by the gain of a toxic function of the expanded polyglutamine tract and neurodegeneration. Fragile X syndrome (CGG repeat), Friedreich's ataxia (GAA repeat) and five SCAs $(1,2$, 3, 6 and 7) (CAG repeat), myotonic dystrophy (DM/ Curschmann-Steinert disease), proximal myotonic myopathy (PROMM or Ricker's syndrome) (CTG repeats) Huntington's disease (CAG repeat), major psychosis $[28,54]$.

Recent findings in genetic research have suggested that a large number of genetic disorders, both genetic syndromes and genetic diseases, that were not previously identified in the medical literature as re- 
lated, may, in fact be related in the gene-typical root cause of the widely-varying, phenotypically-observed disorders.

Mutations in HSD17B4 (also known as D-bifunctional protein), which leads to a fatal form of Zellweger syndrome, have recently also been proposed as the first identified genetic cause of PS by Pierce $e t$ al. [5] and de Launoit et al. [23]. Alström syndrome is a ciliopathy [29]. Other known ciliopathies include primary ciliary dyskinesia, Bardet-Biedl syndrome, polycystic kidney and liver disease, nephronophthisis, Meckel-Gruber syndrome and some forms of retinal degeneration [55].

Gempel et al. [25] reported that the electron transferring flavoprotein dehydrogenase (ETFDH) gene, previously shown to result in another metabolic disorder, glutaric aciduria type II (GAII), leads to a secondary CoQ10 deficiency. Their results indicated that the late-onset form of GAII and the myopathic form of CoQ10 deficiency are allelic diseases.

Aguglia et al. [56], described two brothers with Marinesco-Sjögren's syndrome, both of whom also had very low serum vitamin $\mathrm{E}$ concentrations with an absence of postprandial chylomicrons. Findings on electron microscopy of the intestinal mucosa were consistent with a chylomicron retention disease. They also suggested that both chylomicron retention disease and Marinesco-Sjögren's syndrome are related to defects in a gene crucial for the assembly or secretion of the chylomicron particles, leading to very low serum levels of vitamin $\mathrm{E}$.

\section{PROPOSED TREATMENT MODALITIES}

Individuals with Refsum disease are commonly placed on a Phyt-restricted high-calorie diet and avoid the consumption of fats from ruminant animals and certain fish. Recent research has shown that CYP4 isoform enzymes could help reduce the over-accumulation of Phyt in vivo. Plasmapheresis and vitamin A supplementation are other medical interventions used to treat patients. Sodium 4-phenylbutyrate induces peroxisome proliferation and improves biochemical function (very long chain fatty acid $\beta$-oxidation rates and very long chain fatty acid and plasmalogens levels) in fibroblast cell lines from patients with milder peroxisome biogenesis disorder phenotypes [57,58]. Perera et al. [59] recently proposed intestinal lipase inhibitor, Orlistat, as a novel therapeutic approach to Refsum disease. Leipnitz et al. [60] reported that oxidative stress elicited in vitro by Phyt was prevented by the antioxidants $\alpha$-tocopherol and melatonin. Both DHEA and clofibrate induce peroxisomes and theoretically could be used in the treatment of Zellweger syndrome and PS [61].

In the myopathic form of CoQ10 deficiency, carnitine supplementation and a low-protein low-fat diet were ineffective, and associated with further worsening of symptoms. But combined CoQ10 supplementation with riboflavin $(100 \mathrm{mg} /$ day $)$, resulted in marked and rapid improvement of symptoms. Gironi et al. [39] also reported two brothers who had late-onset progressive ataxia and hypergonadotropic hypogonadism associated with muscle coQ10 deficiency improved on high-dose CoQ10 supplementation. Although there is no current standard treatment, the use of ascorbic acid has been proposed for the treatment of CMT disease, and has shown some benefit in animal models [62]. Recent studies of prospects for gene therapy that adds the proper protein back (gene replacement) are ongoing in many diseases such as Usher syndrome [63].

Declaration of Interest: the authors report no conflicts of interest. The authors alone are responsible for the content and writing of this article.

\section{ACKNOWLEDGMENTS}

We thank to Dr. Nakiye Baysal (from the Department of Otolaryngology at our hospital) for the audiological exam of patient and to Gregory Hammond (psychologist) for editing the (English) language of this text.

\section{REFERENCES}

1. Holmes GA. Form of familial degeneration of the cerebellum. Brain. 1908; 30(4): 466-489.

2. Bösze P, Skripeczky K, Gaál M, Tóth A, László J. Perrault's syndrome in two sisters. Am J Med Genet. 1983; 16(2): 237-241.

3. Amor DJ, Delatycki MB, Gardner RJ, Storey E. New variant of familial cerebellar ataxia with hypergonadotropic hypogonadism and sensorineural deafness. Am J Med Genet. 2001; 99(1): 29-33.

4. Georgopoulos NA, Papapetropoulos S, Chroni E, Papadeas ES, Dimopoulos PA, Kyriazopoulout V, Davis 
MB, Eunson L, Kourounis G, Tzingounist VA. Spinocerebellar ataxia and hypergonadotropic hypogonadism associated with familial sensorineural hearing loss. Gynecol Endocrinol. 2004; 19(2): 105-110.

5. Pierce SB, Walsh T, Chisholm KM, Lee MK, Thornton AM, Fiumara A, Opitz JM, Levy-Lahad E, Klevit RE, King MC. Mutations in the DBP-deficiency protein HSD17B4 cause ovarian dysgenesis, hearing loss, and ataxia of Perrault syndrome. Am J Hum Genet. 2010; 87(2): 282-288.

6. Fehlow P, Walther F. Richards-Rundle syndrome. Klin Paediatr. 1991; 203(3): 184-186.

7. Welsh LW. Alström syndrome: progressive deafness and blindness. Ann Otol Rhinol Laryngol. 2007; 116(4): 281-285.

8. Mathis S, Paquis V, Mesnage V, Balaboï I, Gil R, Gilbert B, Neau JP. Wolfram's syndrome presenting as a cerebellar ataxia Rev Neurol. 2007; 163(2): 197-204.

9. Finsterer J. Mitochondriopathies. Eur J Neurol. 2004; 11(3): 163-186.

10. Nishi Y, Hamamoto K, Kajiyama M, Kawamura I. The Perrault syndrome: clinical report and review. Am J Med Genet. 1988; 31(3): 623-629.

11. Ikezoe K, Yamada A, Takeuchi H, Miki H, Katanaka J. A case of early onset cerebellar ataxia with hearing loss, mental disturbance and primary hypogonadism. Rinsho Shinkeigaku. 1992; 32(9): 1032-1034.

12. De Michele G, Filla A, Striano S, Rimoldi M, Campanella G. Heterogeneous findings in four cases of cerebellar ataxia associated with hypogonadism (Holmes' type ataxia). Clin Neurol Neurosurg. 1993; 95(1): 23-28.

13. Linssen WH, Van den Bent MJ, Brunner HG, Poels PJ. Deafness, sensory neuropathy, and ovarian dysgenesis: a new syndrome or a broader spectrum of Perrault syndrome? Am J Med Genet. 1994; 51(1): 81-82.

14. Koskinen T, Pihko H, Voutilainen R. Primary hypogonadism in females with infantile onset spinocerebellar ataxia. Neuropediatrics. 1995; 26(5): 263-266.

15. Gottschalk ME, Coker SB, Fox LA. Neurologic anomalies of Perrault syndrome. Am J Med Genet. 1996; 65(4): 274-276.

16. Fiumara A, Sorge G, Toscano A, Parano E, Pavone L, Opitz JM. Perrault syndrome: evidence for progressive nervous system involvement. Am J Med Genet A. 2004; 128(3): 246-249.

17. McCarthy DJ, Opitz JM. Perrault syndrome in sisters. Am J Med Genet. 1985; 22(3): 629-631.

18. Kobe C, Kracht LW, Timmermann L, Bachmann J, Schmidt MC. Perrault Syndrome with progressive nervous system involvement. Clin Nucl Med. 2008; 33(12): 922-924.
19. Marlin S, Lacombe D, Jonard L, Leboulanger N, Bonneau D, Goizet C, de Villemeur TB, Cabrol S, Houang M, Moatti L, Feldmann D, Denoyelle F. Perrault syndrome: report of four new cases, review and exclusion of candidate genes. Am J Med Genet A. 2008;146(5):661-664.

20. Pallister PD, Opitz JM. 1979. The Perrault syndrome: Autosomal recessive ovarian dysgenesis with facultative, non-sex-limited sensorineural deafness. Am J Med Genet. 4(3): 239-246.

21. Anttonen AK, Mahjneh I, Hämäläinen RH, LagierTourenne C, Kopra O, Waris L, Anttonen M, Joensuu T, Kalimo H, Paetau A, Tranebjaerg L, Chaigne D, Loenig M, Eeg-Olofsson O, Udd B, Somer M, Somer H, Lehesjoki AE. The gene disrupted in Marinesco-Sjögren syndrome encodes SIL1, an HSPA5 cochaperone. Nat Genet 2005; 37(12): 1309-1311.

22. Beysen D, De Paepe A, De Baere E. FOXL2 mutations and genomic rearrangements in BPES. Hum Mutat. 2009; 30(2): 158-169.

23. de Launoit Y, Adamski J. Unique multifunctional HSD17B4 gene product: 17beta-hydroxysteroid dehydrogenase 4 and D-3-hydroxyacyl-coenzyme A dehydrogenase/hydratase involved in Zellweger syndrome. J Mol Endocrinol. 1999; 22(3): 227-240.

24. Quinzii CM, Hirano M. Coenzyme Q and mitochondrial disease. Dev Disabil Res Rev. 2010; 16(2):183-188.

25. Gempel K, Topaloglu H, Talim B, Schneiderat P, Schoser BG, Hans VH, Pálmafy B, Kale G, Tokatli A, Quinzii C, Hirano M, Naini A, DiMauro S, Prokisch $\mathrm{H}$, Lochmüller H, Horvath R. The myopathic form of coenzyme Q10 deficiency is caused by mutations in the electron-transferring-flavoprotein dehydrogenase (ETFDH) gene. Brain. 2007; 130(Pt. 8): 2037-2044.

26. Finsterer J. Ataxias with autosomal, X-chromosomal or maternal inheritance.Can J Neurol Sci. 2009; 36(4): 409-428.

27. Matsunaga T. Value of genetic testing in the otological approach for sensorineural hearing loss. Keio J Med. 2009; 58(4): 216-222.

28. Wenstrom KD. Fragile $\mathrm{X}$ and other trinucleotide repeat diseases. Obstet Gynecol Clin North Am. 2002; 29(2): 367-388.

29. Girard D, Petrovsky N. Alström syndrome: insights into the pathogenesis of metabolic disorders. Nat Rev Endocrinol. 2011; 7(2): 77-88.

30. Swerdlow RH. The neurodegenerative mitochondriopathies. J Alzheimers Dis. 2009; 17(4): 737-751.

31. Liang WC, Nishino I. State of the art in muscle lipid diseases. Acta Myol. 2010; 29(2): 351-356.

32. Petit C. Usher syndrome: from genetics to pathogenesis. Annu Rev Genomics Hum Genet. 2001; 2: 271-297. 
33. Timmons M, Tsokos M, Asab MA, Seminara SB, Zirzow GC, Kaneski CR, Heiss JD, van der Knaap MS, Vanier MT, Schiffmann R, Wong K. Peripheral and central hypomyelination with hypogonadotropic hypogonadism and hypodontia Neurology, 2006; 67(11): 2066-2069.

34. Crandall BF, Samec L, Sparkes RS. A familial syndrome of deafness, alopecia and hypogonadism. J Pediatr. 1973; 82(3): 461-465.

35. Sohval AR, Soffer LJ. Congenital familial testicular deficiency. Am J Med. 1953; 14(3): 328-348.

36. Woodhouse NJ, Sakati NA. A syndrome of hypogonadism, alopecia, diabetes mellitus, mental retardation, deafness, and ECG abnormalities. J Med Genet. 1983; 20(3): 216-219.

37. Nicolaides P, Appleton RE, Fryer A. Cerebellar ataxia, areflexia, pes cavus, optic atrophy, and sensorineural hearing loss (CAPOS): a new syndrome. J Med Genet. 1996; 33(5): 419-421.

38. Pierce SB, Chisholm KM, Lynch ED, Lee MK, Walsh T, Opitz JM, Li W, Klevit RE, King MC. Mutations in mitochondrial histidyl tRNA synthetase HARS2 cause ovarian dysgenesis and sensorineural hearing loss of Perrault syndrome. Proc Natl Acad Sci USA. 2011; 108(16): 6543-6548.

39. Gironi M, Lamperti C, Nemni R, Moggio M, Comi G, Guerini FR, Ferrante P, Canal N, Naini A, Bresolin N, DiMauro S. Late-onset cerebellar ataxia with hypogonadism and muscle coenzyme Q10 deficiency. Neurology. 2004; 62(5): 818-820.

40. Ienco EC, Simoncini C, Orsucci D, Petrucci L, Filosto M, Mancuso M, Siciliano G. May "mitochondrial eve" and mitochondrial haplogroups play a role in neurodegeneration and Alzheimer's disease? Int J Alzheimers Dis. 2011; 2011: 709061.

41. Leipnitz G, Amaral AU, Zanatta A, Seminotti B, Fernandes CG, Knebel LA, Vargas CR, Wajner M. Neurochemical evidence that phytanic acid induces oxidative damage and reduces the antioxidant defenses in cerebellum and cerebral cortex of rats. Life Sci. 2010; 87(9-10): 275-280.

42. Hogstrom L, Mark J. Fragile X syndrome: relation to premature ovarian failure and infertility treatment. Acta Obstet Gynecol Scand. 2007; 86(2): 244-246.

43. Senderek J, Krieger M, Stendel C, Bergmann C, Moser M, Breitbach-Faller N, Rudnik-Schöneborn S, Blaschek A, Wolf NI, Harting I, North K, Smith J, Muntoni F, Brockington M, Quijano-Roy S, Renault F, Herrmann R, Hendershot LM, Schröder JM, Lochmüller H, Topaloglu H, Voit T, Weis J, Ebinger F, Zerres K. Mutations in SIL1 cause Marinesco-Sjögren syndrome, a cerebellar ataxia with cataract and myopathy. Nat Genet. 2005; 37(12): 1312-1314.
44. Leslie ND. Insights into the pathogenesis of galactosemia. Annu Rev Nutr. 2003; 23: 59-80.

45. Pandolfo M. Friedreich ataxia. Arch Neurol. 2008; 65(10): 1296-1303.

46. Koutnikova H, Campuzano V, Foury F, Dolle P, Cazzalini O, Koenig M. Studies of human, mouse and yeast homologues indicate a mitochondrial function for frataxin. Nat Genet. 1997; 16(4): 345-351.

47. Panov AV, Gutekunst CA, Leavitt BR, Hayden MR, Burke JR, Strittmatter WJ, Greenamyre JT. Early mitochondrial calcium defects in Huntington's disease are a direct effect of polyglutamines. Nat Neurosci. 2002; 5(8): 731-736.

48. Cui L, Jeong H, Borovecki F, Parkhurst CN, Tanese N, Krainc D. Transcriptional repression of PGC- $1 \alpha$ by mutant huntingtin leads to mitochondrial dysfunction and neurodegeneration. Cell. 2006; 127(1): 59-69.

49. Halpin C, Owen G, Gutiérrez-Espeleta G, Sims K, Rehm H. Audiologic features of Norrie disease. Ann Otol Rhinol Laryngol. 2005; 114(7): 533-538.

50. Manaviat MR, Rashidi M, Mohammadi SM. Wolfram Syndrome presenting with optic atrophy and diabetes mellitus: two case reports. Cases J. 2009; 2: 9355.

51. Reiners J, Nagel-Wolfrum K, Jürgens K, Märker T, Wolfrum U. Molecular basis of human Usher syndrome: deciphering the meshes of the Usher protein network provides insights into the pathomechanisms of the Usher disease. Exp Eye Res. 2006; 83(1): 97-119.

52. Kokotas H, Van Laer L, Grigoriadou M, Iliadou V, Economides J, Pomoni S, Pampanos A, Eleftheriades N, Ferekidou E, Korres S, Giannoulia-Karantana A, Van Camp G, Petersen MB. Strong linkage disequilibrium for the frequent GJB2 35delG mutation in the Greek population. Am J Med Genet A. 2008; 146A(22): 2879-2884.

53. Baloh RH, Schmidt RE, Pestronk A, Milbrandt J. Altered axonal mitochondrial transport in the pathogenesis of Charcot-Marie-Tooth disease from mitofusin 2 mutations. J Neurosci. 2007; 27(2): 422-430.

54. Schneider C, Reiners K, Toyka KV. Myotonic dystrophy (DM/Curschmann-Steinert disease) and proximal myotonic myopathy (PROMM/Ricker syndrome). Myotonic muscle diseases with multisystemic manifestations. Nervenarzt. 2001; 72(8): 618-624.

55. Badano JL, Mitsuma N, Beales PL, Katsanis N. The ciliopathies: an emerging class of human genetic disorders. Annu Rev Genomics Hum Genet. 2006; 7: 125-148.

56. Aguglia U, Annesi G, Pasquinelli G, Spadafora P, Gambardella A, Annesi F, Pasqua AA, Cavalcanti F, Crescibene L, Bagalà $\mathrm{A}$, Bono $\mathrm{F}$, Oliveri RL, Valentino $\mathrm{P}$, Zappia M, Quattrone A. Vitamin E deficiency due to 
chylomicron retention disease in Marinesco-Sjögren syndrome. Ann Neurol. 2000; 47(2): 260-264.

57. Baldwin EJ, Gibberd FB, Harley C, Sidey MC, Feher MD, Wierzbicki AS. The effectiveness of long-term dietary therapy in the treatment of adult Refsum disease. J Neurol Neurosurg Psychiatry. 2010; 81(9): 954-957.

58. McGuinness MC, Wei H, Smith KD. Therapeutic developments in peroxisome biogenesis disorders. Expert Opin Investig Drugs. 2000; 9(9): 1985-1992.

59. Perera NJ, Lewis B, Tran H, Fietz M, Sullivan DR. Refsum's disease-use of the intestinal lipase inhibitor, Orlistat, as a novel therapeutic approach to a complex disorder. J Obes. 2011; 2011.pii: Epub 2010 Sep 1.

60. Leipnitz G, Amaral AU, Zanatta A, Seminotti B, Fernandes CG, Knebel LA, Vargas CR, Wajner M. Neurochemical evidence that phytanic acid induces oxida- tive damage and reduces the antioxidant defenses in cerebellum and cerebral cortex of rats. Life Sci. 2010; 87(9-10): 275-280.

61. Adibhatla RM, Hatcher JF. Lipid oxidation and peroxidation in CNS health and disease: from molecular mechanisms to therapeutic opportunities. Antioxid Redox Signal. 2010; 12(1): 125-169.

62. Passage E, Norreel JC, Noack-Fraissignes P, Sanguedolce V, Pizant J, Thirion X, Robaglia-Schlupp A, Pellissier JF, Fontés M. Ascorbic acid treatment corrects the phenotype of a mouse model of Charcot-Marie-Tooth disease. Nat Med. 2004; 10(4): 396-401.

63. Williams DS. Usher syndrome: animal models, retinal function of Usher proteins, and prospects for gene therapy. Vision Res. 2008; 48(3): 433-441. 